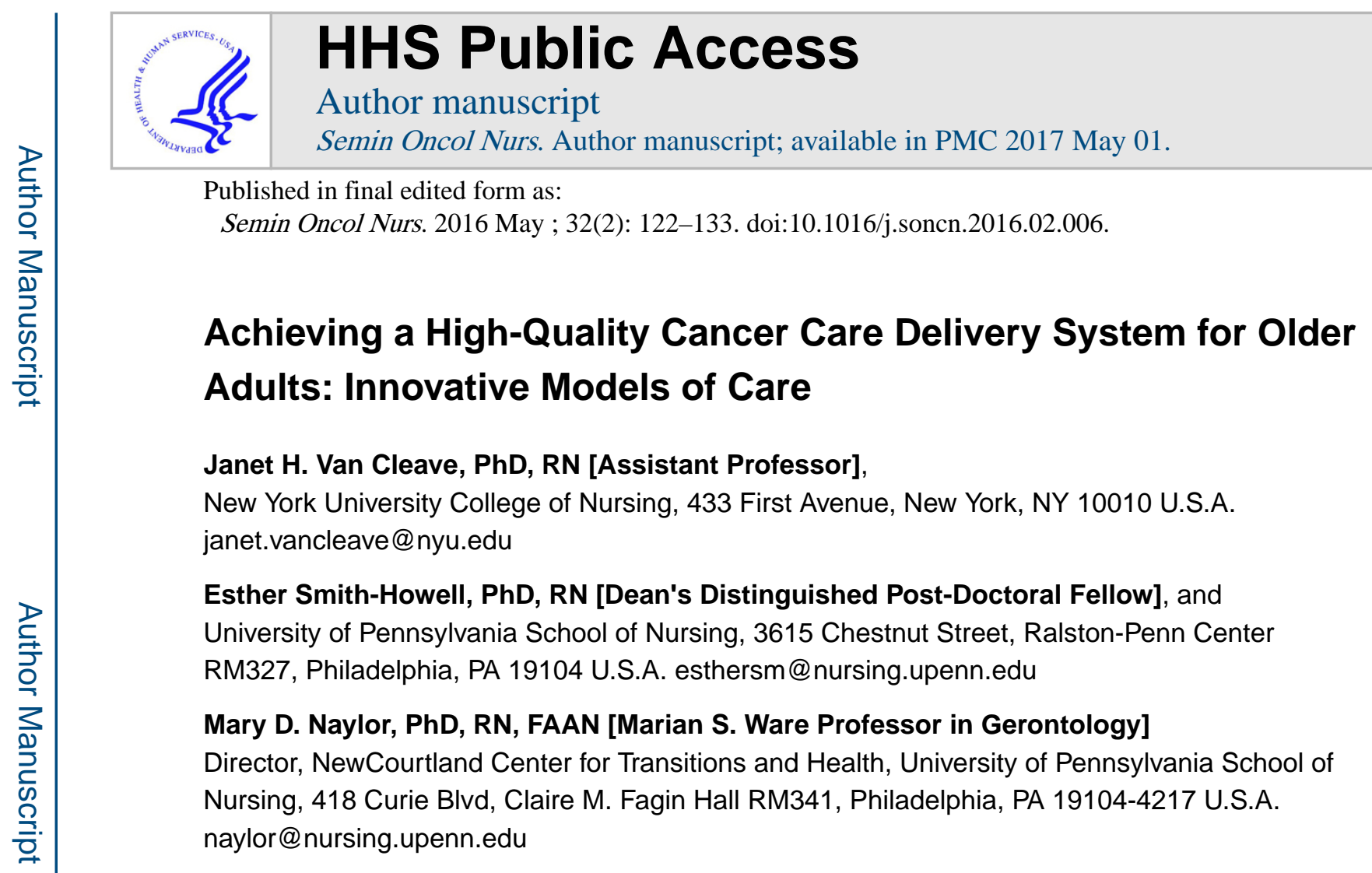

\begin{abstract}
Objectives-To examine innovative models and other research-based interventions that hold potential to assure high-quality care for the growing older adult population living with cancer as one of multiple chronic conditions. Evidence from these care delivery approaches provides a roadmap for the development of future care models.
\end{abstract}

Data Sources-Published peer-reviewed literature, policy analyses, and web-based resources.

Conclusion-Available evidence suggests the need for models that engage patients and their family caregivers, focus on patient's functional capacities, emphasize palliative care, and maximize on the contributions of all team members.

Implications for Nursing Practice-Nursing is uniquely positioned to lead or play a major role in the evolution and implementation of care models targeting older adults with cancer, but must increase their knowledge and skills related to both oncology and geriatrics to maximize their contributions.

\title{
Keywords
}

cancer; model; aging; chronic illness; evidence-based; nurse-led

The publication of the Institute of Medicine Report, Delivering High-Quality Cancer Care: Charting a New Course for A System in Crisis, ${ }^{1}$ stimulated dialogue and debate among

\footnotetext{
Correspondence to: Janet H. Van Cleave.
}

Publisher's Disclaimer: This is a PDF file of an unedited manuscript that has been accepted for publication. As a service to our customers we are providing this early version of the manuscript. The manuscript will undergo copyediting, typesetting, and review of the resulting proof before it is published in its final citable form. Please note that during the production process errors may be discovered which could affect the content, and all legal disclaimers that apply to the journal pertain. 
policy-makers and key stakeholders about the need for system redesign to provide care for a growing older, diverse cancer population. Models that can provide high-quality care for older adults living with cancer and multiple chronic conditions need to be developed, implemented and sustained.

The growth of an older, diverse cancer population in the U.S. can be traced to the National Cancer Act of 1971 that strengthened the mission of the National Cancer Institute to carry out a national initiative against cancer. ${ }^{2}$ These efforts led to a remarkable increase in the 5year cancer survival rate resulting from improved early detection and novel cancer treatments. The 5-year cancer survival rate increased from $49 \%$ in $1975-1977$ to $68 \%$ in 2004-2010. ${ }^{3}$ Accordingly, the number of people living with a cancer diagnosis is projected to grow from the current 14.5 million persons to nearly 19 million by $2024 .{ }^{4}$

Among the people living longer with cancer, profound demographic shifts are contributing to an increasingly elderly and diverse cancer population. The number of adults ages 65 and older is projected to nearly double from the current 48 million to 85 million by $2050 .{ }^{5}$ Currently $53 \%$ of new cancer cases and $69 \%$ of cancer deaths occurring among those ages 65 and over, and the number of new cancer cases in older adults is expected to increase by 67\% between 2010 and 2030. ${ }^{6}$ The Hispanic and Asian populations are projected to nearly double by 2050 . Some minority populations experience a disproportionate rate of growth in the incidence of cancer, resulting in an expected $99 \%$ increase in cancer incidence among all minorities between 2010 and $2030 .^{6}$

This older, diverse cancer population will face several challenges, including paying an increasing share of the cost of their cancer care. With the growth in health care spending, the Centers for Medicare and Medicaid Services (CMS) forecast that health care will grow to nearly one-fifth of the US total budget by $2020 .{ }^{7}$ The cost of cancer care is projected to rise from $\$ 125$ billion in 2010 to $\$ 158$ billion in $2020 .^{8}$ As observed in recent years, rising costs are likely to be accompanied by higher deductibles and copays. ${ }^{7}$ These escalating deductibles and copays may pose barriers to access for cancer care. Even if the percentage of cost born by patients did not change, the overall rise in costs will increase the total dollars that patients must spend for care. Some newer cancer drugs can cost $\$ 10,000$ to $\$ 30,000$ per month. ${ }^{9}$ For older adults, these expensive treatments typically occur when personal income is declining. ${ }^{10}$

In the general Medicare population, $73 \%$ of individuals have two or more chronic conditions that require extensive and expensive health care services, including hospitalizations. ${ }^{11}$ The average per capita health care spending increases with each additional chronic condition. ${ }^{11}$ Similar to the general Medicare population, older adults with cancer have multiple chronic conditions. ${ }^{12}$ This creates a challenge since research has demonstrated that older adults with cancer have a greater number of chronic conditions and use more health resources than their counterparts without cancer. ${ }^{13}$ As the 5-year relative survival rate continues to increase, evidence also suggests that more cancer survivors with multiple chronic conditions will live longer. ${ }^{12}$ The unique needs of a population with multiple complex conditions are often complicated by other health and social risks. 
To identify existing models or research-based interventions that hold potential to deliver high-quality care to an older cancer population, peer-reviewed publications, policy analyses, and web-based resources were reviewed. While not a systematic review, findings are illustrative of the opportunities to redesign care to meet the changing needs of patients with cancer. Evidence from care delivery approaches examined during this review can provide a roadmap for the development of future care models. Specifically, the cross-cutting themes that emerged suggest ways to effectively address the needs of this patient population: engaging patients and family caregivers, emphasizing patients' functional capacities, integrating palliative care, and maximizing the contributions of all team members, with particular attention to the central role of nurses in developing, implementing, and sustaining care models based on these principles. In the section below, the rationale for inclusion of each of these themes is provided with examples of strategies that highlight the critical role of nurses.

\section{Patient and Family Caregiver Engagement}

Patient engagement is now recognized as a key driver to effective care management. ${ }^{14}$ Engagement of chronically ill older adults, including those living with cancer as one of multiple chronic conditions, consists of "deliberate and consistent efforts by health care professionals (clinicians) and organizations (systems) to advance the central role of this patient group in defining what matters to them (i.e. functional status and quality of life), promote informed and shared decision-making regarding their plans of care, foster shared accountability for actions related to these care plans, and assure reciprocal and respectful relationships (p. $457-458)$ ". ${ }^{14}$

In advancing patient engagement, it should be recognized that clinicians and older adults approach decisions about cancer treatment from different viewpoints. Clinicians generally weigh the treatment benefits and risks in the setting of an older adult's decreased life expectancy and decreased ability to tolerate stress. ${ }^{15,16}$ In contrast, older adults often weigh treatment decisions based on the potential for survival versus the potential for loss of physical and/or cognitive function, symptom burden, and caregiver burden. ${ }^{17}$ Research demonstrated that older adults living with cancer as one of multiple chronic conditions may change their decisions over time depending on current health status. For example, in one study the researchers found that some participants that experienced a decline in performance of instrumental activities of daily living were more likely to accept treatment resulting in mild or severe disability. ${ }^{18}$ (Table 1$)^{19-21}$ The study findings demonstrate that an individual's perception of quality of life is complex, dynamic, and influenced by changes in health status. ${ }^{18,22}$ These findings emphasize the importance of ongoing communication among the cancer care team, older adults, and their family caregivers, and the findings also emphasize the need for continuity of care to ensure that advanced care driecvtives reflect patients' values and treatment preferences. ${ }^{1,17}$

An aging diverse population living with cancer is especially vulnerable to breakdowns with care providers due to language and literacy barriers, cultural differences, limited access to essential health services, and distrust in the health care system. ${ }^{23}$ Hence, a prerequisite to 
patient engagement is assessing communication barriers to assure that older adults living with cancer have the ability to obtain, process, and understand basic health information. ${ }^{14}$

Family caregiver engagement also is an important component of providing high-quality cancer care. ${ }^{1}$ As patients with cancer live longer, their family caregivers typically consist of relatives, friends or neighbors that provide assistance but are generally unpaid for these services. These caregivers help patients during treatment to manage side effects from both the cancer and the treatment, often with inadequate preparation ${ }^{24}$, while simultaneously battling their own emotional responses to the patient's diagnosis. ${ }^{25}$ Research indicates that family caregivers that are employed or those caring for patients requiring help with instrumental activities of daily living are at higher risk for experiencing caregiver burden. ${ }^{26}$ Identifying and supporting caregivers experiencing high burden is critical to maintaining family caregiver engagement.

Nurses have developed models that actively engage older adults with multiple chronic conditions and their family caregivers, incorporating the caregiver goals into care plans. One example model is the Transitional Care Model. The Transitional Care Model incorporates patients' and family caregivers' preferences in the care plans as part of the goals of care, an essential element in quality of care for older adults with cancer. Central to this model is the relationship established between patients, family caregivers, and the advanced practice nurse (APN). The APN is the single point of contact to provide continuity of care as the patient transitions from the hospital to their home (or next site of care). Other components of the Transitional Care Model include a comprehensive assessment, development of individualized transitional care plans, and home follow-up care for vulnerable older adults living with multiple chronic conditions. The following case study illustrates the components of the Transitional Care Model and provides a working example of the model:

Mr. Block was a 78-year old man who appreciated a lifetime of excellent health and was a non-user of the healthcare system until he sought treatment for diminished vision secondary to bilateral cataracts. While undergoing cataract surgery, Mr. Block was found to have frequent voiding and urinary retention. On a follow-up visit after the cataract surgery, his provider ordered a Prostate - Specific Antigen test as part of the evaluation of Mr. Block's urinary symptoms. The Prostate specific antigen level was elevated. A biopsy revealed prostate cancer. After a discussion with his provider about his options, Mr. Block chose to undergo surgery and was admitted to the hospital for a total radical prostatectomy.

On Mr. Block's admission to the hospital for the prostate surgery, the electronic health record issued an alert to the transitional care nurse that risk criteria supported Mr. Block's enrollment into the Transitional Care Program. The risk criteria were: four or more active co-existing conditions (hypertension, hyperlipidemia, prostate cancer, visual disturbance following cataract surgery), 3 hospitalizations in the last 3 months and a hospitalization in the last 30 days. Based on the alert issued by the electronic health record, the transitional care nurse (TCN) met with the Mr. and Mrs. Block within a few hours of admission to talk with them about their personal goals and preferences. A comprehensive assessment was performed to understand and anticipate the types of education, assistance, and referrals that would be 
necessary in order for Mr. Block to return home safely and confidently. At baseline, there were no cognitive deficits identified for Mr. Block based on his score of $6 / 6$ on the six-item screen. There were no depressive or anxiety symptoms based on his score of $O$ on the Patient Health Questionnaire-9 (PHQ-9) ${ }^{80}$ He was completely independent in his ADLs ${ }^{20}$ and IADLs. ${ }^{21}$ His symptom score on the Symptom Bother Scale ${ }^{81}$ was $4 / 13$ identifying only aching and poor hearing as issues. He rated his overall quality of life and his health as excellent. He stated that he never feels downhearted or depressed.

Mr. Block was married and lived in a single-family home with his wife and one of their adult sons. He spent his time caring for their grounds and garden. He enjoyed walking and spending time with his wife. Mrs. Block served as the primary caregiver for the patient. Mrs. Block also scored a O on the PHQ-9. She was completely independent in her ADLs and IADLs. Her symptoms score was a 3/42 with only occasional left knee pain and poor vision as issues. She also reported her quality of life and health as excellent. Her Zarit score ${ }^{82}$ was $5 / 88$ with very little caregiver burden identified.

All of these findings were reviewed with the healthcare team for additional insights and recommendations, and a report was included in the patient's electronic health record. The patient and family caregiver were visited daily throughout the admission by the TCN and were discussed in discharge planning meetings with the healthcare team. All education during the hospitalization occurred with both Mr. and Mrs. Block, and they were provided several opportunities to demonstrate their understanding of information and necessary skills through teach back with the healthcare team. Coordination of all identified supplies and services was accomplished by the TCN prior to the patient leaving the hospital. The patient and family caregiver were provided contact information for all providers, including the home healthcare nurse that would be assisting in their care. Mr. and Mrs. Block identified their goals, which were entered into the electronic health record for review by all providers. This included a safe transition to home with completion of the recovery process. Mr. Block's primary goal, though, was a return to yard work.

Mr. and Mrs. Block were visited in their home a total of 5 times and had 4 telephone calls with the TCN. In addition, he also received the services of a visiting nurse for catheter removal. All follow-up appointments were appropriately scheduled. The Five-Wishes ${ }^{83}$ document for advanced care planning was provided for both Mr. and Mrs. Block. This form was reviewed in detail and completed with both individuals and a copy scanned into the electronic health record and sent to Mr. Block's primary care provider.

Mr. and Mrs. Block were able to achieve all of their goals, and, over time, Mr. Block returned to his yard work. All information related to Mr. Block's transition was shared with the healthcare team via dashboards on Mr. Block's electronic health record.

A few months after completing the transitional care program, Mr. Block's PSA began to rise. He was referred for radiation treatment. The TCN was contacted 
when he began having irritative voiding symptoms during radiation. The TCN was able to offer suggestions to alleviate his voiding symptoms in order to complete his radiation treatment. There were no interruptions in his treatment or need for emergency department or rehospitalization use for one year after his index hospital discharge. Mr. Block returned to his preoperative level of function.

In three National Institutes of Health (NIH)-funded randomized controlled trials (RCTs), the Transitional Care Model consistently demonstrated improved health outcomes and reduced total health care costs. ${ }^{27-29}$ Specifically, the Transitional Care Model resulted in reductions in all-cause rehospitalization rates, enhanced patient care experiences, improved physical function and quality of life, and health care savings averaging $\$ 5,000$ per adult at one year post-enrollment (after accounting for the intervention's costs). ${ }^{23}$

The Transitional Care Model also has been tested among older adults with cognitive impairment, a population that can be especially challenging to both oncology and geriatric practitioners. ${ }^{30}$ In this NIH-funded comparative effectiveness study, researchers found that the time to first rehospitalization was significantly longer for those in the Transitional Care Model group relative to a similar group that received augmented standard care and marginally better compared to a group that received care from specially trained resource nurses. On average, though not significant, participants that received the Transitional Care Model experienced higher scores in activities of daily living and instrumental activities of daily living than those who received either of the other interventions. ${ }^{30}$

\section{Focus on Functional Capacities}

Function is a central concept for both oncology and geriatrics disciplines (See Table 1). An older adults' function impacts ability to live independently and enjoy a high-quality of life as well as their use of both health and long-term services. Study findings reveal that chronically ill older adults with functional deficits use a higher percentage of health resources than chronically ill older adults who do not have these limitations. ${ }^{31}$ In addition to independent living and use of health resources, older adults' function can predict ability to tolerate cancer treatment. ${ }^{32,33}$ For example, the investigators of a study of elderly patients with non-small cell lung cancer undergoing chemotherapy found that pre-treatment quality of life ratings and instrumental activities of daily living significantly predicted survival. ${ }^{34}$

With the evidence supporting the importance of functional status among older adults living with cancer, incorporating evidence-based interventions designed to assess and improve or maintain function is of great importance. A report of an APN-led intervention for older adults following cancer surgery offers one example of the positive effects of integrating a focus on function in care delivery models. In this study, patients received an individualized home care intervention administered by APNs after surgery, while a control group received standard ambulatory care. The intervention consisted of three home visits and five telephone calls conducted by APNs with patients and family members. As part of this intervention, APNs monitored participants' physical, emotional, and functional status along with providing counseling, securing community services, and making referrals to interprofessional colleagues. APNs were available on a 24-hour basis; they consulted with 
physicians and intervened quickly if complications occurred. The study findings demonstrated that the APN intervention was significantly associated with improved post operative survival among those patients with late stage cancer. ${ }^{35}$

Geriatric nurse-led teams have developed interventions to improve function and, promote older adults' ability to maintain independence. For example, an ongoing CMS project is evaluating the Community Aging in Place, Advancing Better Living for Elders (CAPABLE), an innovation designed to overcome functional and home environmental barriers among older adults. CAPABLE is a structured program, composed of an occupational therapist, registered nurse, and handy man. The program is delivered at participants' homes and individualized according to participants' functional goals. ${ }^{36}$ If preliminary trends continue, the CAPABLE intervention offers great promise to maintain function or delay the progression of functional deficits in older adults with cancer, enabling them to remain in their homes. ${ }^{36}$

\section{Palliative Care}

Palliative care consists of "patient- and family-centered care that optimizes quality of life by anticipating, preventing, and treating suffering" (National Quality Forum, 2006, p. 6). ${ }^{37} \mathrm{~A}$ central tenet of effective palliative care is the respect for each individual demonstrated by clinicians throughout the course of illness and during the dying process, and for their families following the person's death. ${ }^{1,37}$ The ideal palliative care model provides a vehicle for patients, families, and palliative and non-palliative care clinicians to collaborate and communicate about patient care and advanced care planning. Thus, models that incorporate palliative care interventions enable treatment to align more closely with older adults' needs and preferences.

Evidence supports that early palliative care for advanced stage cancer improves survival. ${ }^{38-41}$ Researchers have also found that palliative care consultations for hospitalized advanced cancer patients with multiple chronic conditions are significantly associated with reduced direct hospital costs and larger average cost savings for those with higher comorbidity burden. ${ }^{42}$ Oncology nurses are among the leaders in developing such palliative care interventions. ${ }^{40,41}$ For example, a nurse-led RCT was conducted to determine the effect of early versus delayed palliative care on quality of life, symptom impact, mood, 1-year survival, and resource use. Patients with advanced cancer were assigned to receive an inperson palliative care consultation, 6 weekly structured palliative care telehealth nurse coaching sessions, and then monthly follow-up at either early enrollment or 3 months later. At one year, participants assigned to the early palliative care intervention had significantly increased 1-year survival rates than those who received delayed palliative care. ${ }^{41}$ Together, these findings illustrate the need for health care leadership and delivery systems to adopt or adapt these models and policy changes to sustain their use. ${ }^{42}$

Another important component of palliative care is patient-centered symptom management. ${ }^{37}$ For older adults, therapy decisions are influenced by whether or not a treatment will increase the burden of symptoms, especially fatigue and pain. ${ }^{17}$ Cancer-related fatigue is one of the most prevalent symptoms. With advanced cancer, the prevalence of fatigue may be greater 
than $50 \%$ to $70 \% .{ }^{16}$ Multiple factors can contribute to fatigue, including pain. A metaanalysis showed that $59 \%$ of patients undergoing cancer treatment (64\% of patients with advanced disease; $33 \%$ of patients after curative treatment) experience pain. ${ }^{43}$ Controlling cancer pain begins with a comprehensive assessment. ${ }^{44}$ However, organizational and payment policies may limit the time that providers have to conduct such assessments. ${ }^{44}$ As a result, providers may underestimate the severity of cancer pain, thus patients may experience unnecessary suffering. ${ }^{45-48}$ Until recently, older adults with complex care needs have been excluded from clinical trials testing symptom management strategies. ${ }^{49}$ Clinical trials are needed that focus on the physical and psychological symptoms common among older adults living with cancer as one of multiple chronic conditions. These clinical trials can guide the development of evidence - based guidelines, changes in protocols, and development of innovative care models for symptom management. ${ }^{44}$

The large volume of data in electronic health records and the evolving field of data science create promising avenues to advance knowledge regarding symptom management in older adults living with cancer. For example, prostate cancer researchers used natural language programming (NLP) to illuminate severe pain patterns in the medical record documentation. ${ }^{50}$ To identify these pain patterns, the researchers developed NLP vocabulary and algorithms to detect pain concepts in the unstructured text. Oncology providers and researchers can apply these methods to illuminate symptom patterns and potentially improving symptom management strategies for older adults living with cancer.

However, integrating self-report symptom questionnaires into the medical record has challenges. ${ }^{51}$ Although health systems may recognize the importance of the questionnaires, some medical record systems lack the ability to collect or display self-report questionnaire data that allows quick and easy access. Moreover, some patients are reluctant to include selfreport data in their medical records. ${ }^{51}$ A nurse-led interprofessional team is advancing the use of a computerized algorithm-based clinical decision support system to improve evidence-based management for lung cancer symptom assessment. ${ }^{52}$ The researchers found a high rate of patient completion of surveys (84\%) and high rate of information delivery to providers $(90 \%)$. However, the researchers also found a low rate of providers' adherence to recommendations (57\%). The study findings demonstrate the potential to implement decision support systems for evidence-based symptom management for lung cancer. Although more research is needed to improve adherence to recommendations, these systems have the potential to improve the quality of cancer care through delivery of evidence-based decision advice directly to both providers and patients. ${ }^{53}$

Older adults living with cancer may have difficulty traveling to cancer centers, either in the community or academic medical centers. Thus, symptom management interventions need to be delivered where the patients live. Oncology nurse researchers have developed nurse-led interventions for cancer symptom management that overcome this potential barrier. The intervention was developed to assist patients to acquire self-management knowledge, as well as skills and behaviors to address symptom problems. ${ }^{54}$ Compared with conventional care alone, the intervention effectively decreased symptoms among patients reporting high symptom severity. Building on this foundation, the researchers conducted a secondary analysis of two randomized trials comparing a nurse-led intervention to a coach or 
automated system. The team found that both approaches were effective in reducing symptom severity, however the intervention delivered by a person was more effective at engaging patients $\geq 75$ years old, while an automated system was more effective at engaging those $\leq$ 45 years old. ${ }^{54,55}$ These findings suggest that older adults may benefit from personalized interventions tailored to their individualized needs and desires. ${ }^{55}$

\section{Team-Based Care}

Workforce shortages mandate the need for efficient and effective interprofessional teambased care models to provide care that aligns with the needs and preferences of older adults living with cancer as one of multiple chronic conditions. This care may include primary care services for ongoing treatment of chronic conditions, hospitalizations for acute illnesses, and long-term care to assist with self-care activities. Currently, there is a lack of health care professionals trained in primary care, geriatrics, and oncology. This workforce shortage will likely continue into the future, as analyses of workforce trends demonstrate that, by 2020, the U.S. may face a shortage of 45,400 primary care physicians and 46,100 medical specialists. ${ }^{56}$ The following care models that rely on a range of health professionals provide examples of the effectiveness of interprofessional team-based care to provide high-quality cancer care.

The Stephen and Sandra Sheller 11th Street Family Health Services combines primary care and family- and community-centered services that are important for older adults with cancer. ${ }^{57}$ This nurse-led model promotes health for a predominately low-income African American community in Philadelphia, Pennsylvania. ${ }^{57}$ The $11^{\text {th }}$ Street Family Health Services provides integrated care through a single point of access and an interprofessional team. The $11^{\text {th }}$ Street Family Health Services' comprehensive care includes behavioral health, dental care, health and wellness programs, physical therapy, and primary care via partnerships including the Partnership for Community Based Care, Family Practice and Counseling Network, The Philadelphia Housing Authority, and Drexel University. ${ }^{57}$ In 2009, the 11th Street Family Health Services provided over 14,000 primary care visits. During an 18-month period, the benefits of the care model were assessed. During that period, the percentage of patients with a hemoglobin A1c level $>9$ was decreased from $70 \%$ to $30 \%$ and the percentage of patients with blood pressure lower than 140/90 improved from 30\% to $70 \%$. Further, patient satisfaction evaluations consistently ranked care in the 4 to 5 range on a five-point scale. ${ }^{58}$

Hospitalized older adults, including those with cancer, are at high risk for loss of function and institutionalization. ${ }^{59,60}$ Research has demonstrated that when interprofessional teams use the complementary principles of quality improvement and geriatric care, there is an increase in the older adults ability to perform activities of daily living at time of discharge and there is a reduced need to discharge to long-term care facilities. ${ }^{60}$ Therefore, researchers conducted a secondary data analysis to investigate the effect of geriatric inpatient care for hospitalized older adults with cancer. ${ }^{61}$ The parent study consisted of a randomized $2 \times 2$ factorial trial with participants assigned to one of four groups: usual inpatient/usual outpatient care, geriatric inpatient/usual outpatient care, usual inpatient care/geriatric outpatient care, or geriatric inpatient/geriatric outpatient care. The geriatric care team 
included a geriatric medicine attending physician, fellow or intern, a nurse practitioner, and a social worker. Additionally, a clinical pharmacologist, dietician, physical or occupational therapist, and supervised trainees from optometry, dentistry, and audiology were involved as members of an extended team. For the secondary data analysis, the researchers conducted two analyses of health related quality of life outcomes at discharge and 12 month follow-up time among a subset of study participants who had a diagnosis of cancer. The two analyses consisted of: 1) comparing participants with cancer who received geriatric inpatient care with participants with cancer who received usual inpatient care, and 2) comparing participants with cancer who received geriatric outpatient care with participants with cancer who received usual outpatient care. The researchers found that older adults with cancer who received geriatric inpatient care had significantly less emotional limitation and bodily pain at discharge than those who received usual inpatient care. Moreover, the older adults with cancer that received the geriatric-focused inpatient care reported less physical pain at 12 month follow-up time than those who received usual inpatient care. For the analysis of outpatient care, the researchers found those who received geriatric outpatient care reported significantly worse mental health at discharge than those who received usual outpatient care. While not conclusive, the study findings suggest the benefits of providing focused inpatient geriatric care for hospitalized older adults with cancer. ${ }^{61}$

At some point in their trajectory, many older adults with complex conditions including cancer will require long-term services and supports. The Program of All-Inclusive Care for the Elderly (PACE) ${ }^{62,63}$ is a community-managed care program for frail, chronically ill older adults whose cognitive and function limitations make them eligible for nursing home care. The PACE program origins can be traced to a 1971 On Lok program in the San Francisco Chinatown-North Beach district. The community leaders that organized the PACE program believed that combining social services with a senior day center could help frail older adults avoid nursing home placement. The PACE program provides primary care, acute care, and long-term care using a day center with a full service medical clinic. An interdisciplinary team consisting of primary care physicians, nurse practitioners, clinic nurses, home health nurses, social workers, occupational and physical therapists, dietitians, health workers, recreation therapists, and transportation workers provides the care for patients. Together, the interprofessional team collaborates to identify individual participant needs and formulate appropriate treatment plans. Studies of PACE programs have demonstrated improved functional outcomes, reduced utilization of institutional care, and improved survival. ${ }^{62,64,65}$ However, patient outcomes may differ according to the PACE site and the team performance. ${ }^{64}$ Nursing has been instrumental in promoting the use of the PACE model. The American Academy of Nursing designated two PACE programs, Living Independently for Elders (LIFE) ${ }^{66}$ and On Lok Senior Health Services, ${ }^{67}$ as exemplars of nurse-led innovative models that promote health and provide care to diverse and underserved populations. ${ }^{68}$

\section{Building the Nursing Workforce of the Future}

With the clinical knowledge and presence across all care settings, nursing is uniquely positioned to lead and play a major role in the evolution and implementation of care models targeting the growing diverse and older cancer population. ${ }^{69}$ However, to fulfill this role, nursing must build a workforce that meets the challenges of a rapidly changing health care 
system. As a result of the implementation of the Affordable Care Act ${ }^{70}$ and payment reform, ${ }^{69}$ health payers are shifting away from fee-for-service payments that reward volume toward paying for value and health outcomes achieved. ${ }^{71}$ In January 2015, the U. S. Department of Health and Human Services Secretary Sylvia M. Burwell announced that by 2018 at least 50\% of Medicare payments will be tied to quality or value through alternative payment models, such as Accountable Care Organizations. ${ }^{72}$ As a result, health care providers are redesigning systems to include new roles and settings for care delivery that will involve care coordination, care management, and patient navigation. ${ }^{69}$ These new developmetns will occur across the health continuum in both community and acute care settings. These new roles will include early detection and prevention of new cancers, primary care, home- and community-based care, transitional care, and palliative care.

To lead or play a major role in the changing health care system, nursing will need to increase their competencies (knowledge, skills, and behaviors) and strengthen their ability to: 1) engage patients and family members in decision-making; 2 ) manage care complexity using holistic approaches that emphasize enhanced palliative care and improved function; and 3) provide care that values the use of teams to optimize the health and quality of life outcomes of this population..$^{73}$ These competencies include care coordination, transition management, use of evidence-based practices, and strategies related to performance improvement. Most important, nurses must increase their skills in developing interprofessional collaborations, engaging patients and family caregivers, responding to interprofessional colleagues, and connecting with the community. ${ }^{69,74}$

The nursing workforce is already undergoing changes to adapt to the new health care system. The Institute of Medicine report on The Future of Nursing: Leading Change, Advancing Health, ${ }^{75}$ spawned initiatives to increase the number of baccalaureate prepared nurses entering the nursing workforce. ${ }^{76}$ The nursing profession is moving toward broadening nurses' scopes of practice, allowing them to work to their full level of training.

While these changes represent important steps in building the capacity of the nursing workforce to achieve high-quality care for older adults living with cancer, more work is needed. Educational system redesign is needed to properly prepare nurses for their new roles and responsibilities in care coordination and transition management. Most important, this redesign must include education and lifelong career development opportunities in interprofessional team-based care that incorporates oncology and geriatric principles. ${ }^{77}$ Moreover, health care licensure, certification, and accreditation requirements need to better reflect nursing's emerging roles. ${ }^{69}$

Furthermore, oncology nurses must be partners in the redesign of a healthcare system that emphasizes value. It is important to note that the Oncology Nursing Society is already present in many national forums, coalitions, and alliances. In addition, the Oncology Nursing Society currently sponsors a representative for the Institute of Medicine's National Cancer Policy Forum. ${ }^{78,79}$ Continued investment in leadership development and identification of opportunities for nurses to be active participants in all forums focused on system redesign is essential to optimize nursing's critical role in providing high-quality care for a growing older, diverse cancer population. 


\section{CONCLUSION}

Current systems of care are inadequate to meet the needs of a growing older and diverse cancer population. Innovative care models and other nurse-led interventions have generated evidence to guide system redesign. The evidence indicates the need for models that engage patient and family caregivers, focus on functional capacities, provide palliative care throughout the cancer trajectory, and provide high-quality interprofessional team-based care. Strategies are needed to continue to build the knowledge and skills of the nursing workforce to achieve a high-quality cancer delivery system for older adults.

\section{REFERENCES}

1. IOM (Institute of Medicine). Delivering high-quality cancer care: Charting a new course for a system in crisis. Washington DC: The National Academies Press; 2013.

2. National Cancer Institute. [Accessed December 31, 2015] The national cancer act of 1971. http:// legislative.cancer.gov/history/phsa/1971

3. National Cancer Institute: Surveillance, Epidemiology, and End Results Program. [Accessed December 31, 2015] SEER stat fact sheets: All cancer sites. http://seer.cancer.gov/statfacts/html/ all.html

4. American Cancer Society. Cancer facts \& figures 2015. Atlanta: American Cancer Society; 2015.

5. United States Census Bureau. [Accessed December 14, 2015] Population projections. http:// www.census.gov/population/projections/data/national/2012/summarytables.html

6. Smith BD, Smith GL, Hurria A, Hortobagyi GN, Buchholz TA. Future of cancer incidence in the united states: Burdens upon an aging, changing nation. J Clin Oncol. 2009; 27(17):2758-2765. [PubMed: 19403886]

7. The Henry J. Kaiser Family Foundation. Health care costs: A primer. http://kff.org/health-costs/ issue-brief/health-care-costs-a-primer/. Updated 2012.

8. Mariotto AB, Yabroff KR, Shao Y, Feuer EJ, Brown ML. Projections of the cost of cancer care in the united states; 2010-2020. J Natl Cancer Inst. 2011; 103(2):117-128. [PubMed: 21228314]

9. Young RC. Value-based cancer care. N Engl J Med. 2015; 373:2593-2595. [PubMed: 26580243]

10. Prince MJ, Wu F, Guo Y, et al. The burden of disease in older people and implications for health policy and practice. Lancet. 2015; 385:549-562. [PubMed: 25468153]

11. Anderson, G. Chronic care: Making the case for ongoing care. Princeton, NJ: Robert Wood Johnson Foundation; 2010.

12. Leach CR, Weaver KE, Aziz NM, et al. The complex health profile of long-term cancer survivors: Prevalence and predictors of comorbid conditions. J Cancer Surviv. 2015; 9(2):239-251. [PubMed: 25319681]

13. Hewitt M, Rowland JH, Yancik R. Cancer survivors in the United States: Age, health, and disability. J Gerontol A Biol Sci Med Sci. 2003; 58(1):82-91. [PubMed: 12560417]

14. Naylor MD, Hirschman KB, O'Connor M, Barg R, Pauly MV. Engaging older adults in their transitional care: What more needs to be done? J Comp Eff Res. 2013; 2(5):457-468. [PubMed: 24236743]

15. Guiding principles for the care of older adults with multimorbidity: An approach for clinicians: American geriatrics society expert panel on the care of older adults with multimorbidity. J Am Geriatr Soc. 2012; 60(10):E1-E25. [PubMed: 22994865]

16. National Comprehensive Cancer Network. NCCN guidelines older adult oncology version 2. 2015 http://www.nccn.org/professionals/physician_gls/f_guidelines.asp. Updated 2015.

17. Fried TR, Bradley EH. What matters to seriously ill older persons making end-of-life treatment decisions?: A qualitative study. J Palliat Med. 2003; 6(2):237-244. [PubMed: 12854940]

18. Fried TR, Byers AL, Gallo WT, et al. Prospective study of health status preferences and changes in preferences over time in older adults. Arch Intern Med. 2006; 166(8):890-895. [PubMed: 16636215] 
19. Leidy NK. Functional status and the forward progress of merry-go-rounds: Toward a coherent analytical framework. Nurs Res. 1994; 43(4):196-202. [PubMed: 8047422]

20. Katz S, Ford AB, Moskowitz RW, Jackson BA, Jaffe MW. Studies of illness in the aged. the index of the ADL: A standardized measure of biological and psychological function. JAMA. 1963; 185:914-919. [PubMed: 14044222]

21. Lawton MP. Scales to measure competence in everyday activities. Psychopharmacology Bull. 1988; 24(4):609-614.

22. Sprangers MA, Schwartz CE. Integrating response shift into health-related quality of life research: A theoretical model. Soc Sci Med. 1999; 48(11):1507-1515. [PubMed: 10400253]

23. Naylor MD. Advancing high value transitional care: The central role of nursing and its leadership. Nurs Adm Q. 2012; 36(2):115-126. [PubMed: 22407204]

24. Reinhard, SC.; Levine, C.; Samis, S. Home alone: Family caregivers providing complex care chronic care. Washington, D. C.: AARP Public Policy Institute; 2012.

25. Given, BA.; Given, CW. Caregiving for patients with cancer. In: Burgio, LD.; Gaugler, JE.; Hilgeman, MM., editors. The spectrum of family caregiving for adults and elders with chronic illness. New York: Oxford; 2016.

26. Hsu T, Loscalzo M, Ramani R, et al. Factors associated with high burden in caregivers of older adults with cancer. Cancer. 2014; 120(18):2927-2935. [PubMed: 24898093]

27. Naylor MD. Comprehensive discharge planning for hospitalized elderly: A pilot study. Nurs Res. 1990; 39(3):156-161. [PubMed: 2188217]

28. Naylor MD, Brooten D, Campbell R, et al. Comprehensive discharge planning and home follow-up of hospitalized elders: A randomized clinical trial. JAMA. 1999; 281(7):613-620. [PubMed: 10029122]

29. Naylor MD, Brooten DA, Campbell RL, Maislin G, McCauley KM, Schwartz JS. Transitional care of older adults hospitalized with heart failure: A randomized, controlled trial. J Am Geriatr Soc. 2004; 52(5):675-684. [PubMed: 15086645]

30. Naylor MD, Hirschman KB, Hanlon AL, et al. Comparison of evidence-based interventions on outcomes of hospitalized, cognitively impaired older adults. J Comp Eff Res. 2014; 3(3):245-257. [PubMed: 24969152]

31. Alecxih, L.; Shen, S.; Chan, I.; Taylor, D.; Drabek, J. Individuals living in the community with chronic conditions and functional limitations: A closer look. Falls Church, VA: The Lewin Group; 2010.

32. Extermann M, Boler I, Reich RR, et al. Predicting the risk of chemotherapy toxicity in older patients: The chemotherapy risk assessment scale for high-age patients (CRASH) score. Cancer. 2012; 118(13):3377-3386. [PubMed: 22072065]

33. Hurria A, Togawa K, Mohile SG, et al. Predicting chemotherapy toxicity in older adults with cancer: A prospective multicenter study. J Clin Oncol. 2011; 29(25):3457-3465. [PubMed: 21810685]

34. Maione P, Perrone F, Gallo C, et al. Pretreatment quality of life and functional status assessment significantly predict survival of elderly patients with advanced non-small-cell lung cancer receiving chemotherapy: A prognostic analysis of the multicenter italian lung cancer in the elderly study. J Clin Oncol. 2005; 23(28):6865-6872. [PubMed: 16192578]

35. McCorkle R, Strumpf NE, Nuamah IF, et al. A specialized home care intervention improves survival among older post-surgical cancer patients. J Am Geriatr Soc. 2000; 48(12):1707-1713. [PubMed: 11129765]

36. Szanton SL, Wolff JL, Leff B, et al. Preliminary data from community aging in place, advancing better living for elders, a patient-directed, team-based intervention to improve physical function and decrease nursing home utilization: The first 100 individuals to complete a centers for medicare and medicaid services innovation project. J Am Geriatr Soc. 2015; 63(2):371-374. [PubMed: 25644085]

37. National Quality Forum. A national framework and preferred practices for palliative and hospice care quality. Washington, D. C.: National Quality Forum; 2006.

38. Temel JS, Greer JA, Muzikansky A, et al. Early palliative care for patients with metastatic nonsmall-cell lung cancer. N Engl J Med. 2010; 363(8):733-742. [PubMed: 20818875] 
39. Zimmermann C, Swami N, Krzyzanowska M, et al. Early palliative care for patients with advanced cancer: A cluster-randomised controlled trial. Lancet. 2014; 383(9930):1721-1730. [PubMed: 24559581]

40. Bakitas M, Lyons KD, Hegel MT, et al. Effects of a palliative care intervention on clinical outcomes in patients with advanced cancer: The project ENABLE II randomized controlled trial. JAMA. 2009; 302(7):741-749. [PubMed: 19690306]

41. Bakitas MA, Tosteson TD, Li Z, et al. Early versus delayed initiation of concurrent palliative oncology care: Patient outcomes in the ENABLE III randomized controlled trial. J Clin Oncol. 2015; 33(13):1438-1445. [PubMed: 25800768]

42. May P, Garrido MM, Cassel JB, et al. Palliative care teams' cost-saving effect is larger for cancer patients with higher numbers of comorbidities. Health Aff. 2016; 35(1):44-53.

43. van den Beuken-van Everdingen MH, de Rijke JM, Kessels AG, Schouten HC, van Kleef M, Patijn J. Prevalence of pain in patients with cancer: A systematic review of the past 40 years. Ann Oncol. 2007; 18(9):1437-1449. [PubMed: 17355955]

44. Institute of Medicine. Relieving pain in america: A blueprint for transforming prevention, care, education, and research. Washington, D. C.: The National Academies Press; 2011.

45. Nakaguchi T, Okuyama T, Uchida M, et al. Oncology nurses' recognition of supportive care needs and symptoms of their patients undergoing chemotherapy. Jpn J Clin Oncol. 2013; 43(4):369-376. [PubMed: 23365112]

46. Okuyama T, Akechi T, Yamashita H, et al. Oncologists' recognition of supportive care needs and symptoms of their patients in a breast cancer outpatient consultation. Jpn J Clin Oncol. 2011; 41(11):1251-1258. [PubMed: 22003206]

47. Shin DW, Kim SY, Cho J, et al. Discordance in perceived needs between patients and physicians in oncology practice: A nationwide survey in Korea. J Clin Oncol. 2011; 29(33):4424-4429. [PubMed: 22010016]

48. Cleeland CS, Sloan JA. ASCPRO Organizing Group. Assessing the symptoms of cancer using patient-reported outcomes (ASCPRO): Searching for standards. J Pain Symptom Manage. 2010; 39(6):1077-1085. [PubMed: 20538189]

49. Talarico L, Chen G, Pazdur R. Enrollment of elderly patients in clinical trials for cancer drug registration: A 7-year experience by the US food and drug administration. J Clin Oncol. 2004; 22(22):4626-4631. [PubMed: 15542812]

50. Heintzelman NH, Taylor RJ, Simonsen L, et al. Longitudinal analysis of pain in patients with metastatic prostate cancer using natural language processing of medical record text. J Am Med Inform Assoc. 2013; 20(5):898-905. [PubMed: 23144336]

51. McGlynn EA, Lieu TA, Durham ML, et al. Developing a data infrastructure for a learning health system: The PORTAL network. J Am Med Inform Assoc. 2014; 21(4):596-601. [PubMed: 24821738]

52. Cooley ME, Blonquist TM, Catalano PJ, et al. Feasibility of using algorithm-based clinical decision support for symptom assessment and management in lung cancer. J Pain Symptom Manage. 2015; 49(1):13-26. [PubMed: 24880002]

53. Murphy EV. Clinical decision support: Effectiveness in improving quality processes and clinical outcomes and factors that may influence success. Yale J Biol Med. 2014; 87(2):187-197. [PubMed: 24910564]

54. Given C, Given B, Rahbar M, et al. Effect of a cognitive behavioral intervention on reducing symptom severity during chemotherapy. J Clin Oncol. 2004; 22(3):507-516. [PubMed: 14752074]

55. Sikorskii A, Given CW, Siddiqi AE, et al. Testing the differential effects of symptom management interventions in cancer. Psychooncology. 2015; 24(1):25-32. [PubMed: 24737669]

56. Kirch DG, Henderson MK, Dill MJ. Physician workforce projections in an era of health care reform. Ann Rev Med. 2012; 63:435-445. [PubMed: 21888514]

57. Drexel University College of Nursing and Health Professions. Stephen and sandra sheller 11th street family health services. http://drexel.edu/cnhp/practices/11th-street/.

58. Gerrity P. And to think that it happened on 11th street: A nursing approach to community-based holistic care and health care reform. Altern Ther Health Med. 2010; 16(5):62-67. [PubMed: 20882733] 
59. Gillick MR, Serrell NA, Gillick LS. Adverse consequences of hospitalization in the elderly. Soc Sci Med. 1982; 16(10):1033-1038. [PubMed: 6955965]

60. Landefeld CS, Palmer RM, Kresevic DM, Fortinsky RH, Kowal J. A randomized trial of care in a hospital medical unit especially designed to improve the functional outcomes of acutely ill older patients. N Engl J Med. 1995; 332(20):1338-1344. [PubMed: 7715644]

61. Rao AV, Hsieh F, Feussner JR, Cohen HJ. Geriatric evaluation and management units in the care of the frail elderly cancer patient. J Gerontol A Biol Sci Med Sci. 2005; 60(6):798-803. [PubMed: 15983186]

62. Eng C, Pedulla J, Eleazer GP, McCann R, Fox N. Program of all-inclusive care for the elderly (PACE): An innovative model of integrated geriatric care and financing. J Am Geriatr Soc. 1997; 45(2):223-232. [PubMed: 9033525]

63. Friedman SM, Steinwachs DM, Temkin-Greener H, Mukamel DB. Informal caregivers and the risk of nursing home admission among individuals enrolled in the program of all-inclusive care for the elderly. Gerontologist. 2006; 46(4):456-463. [PubMed: 16920999]

64. Mukamel DB, Temkin-Greener H, Delavan R, et al. Team performance and risk-adjusted health outcomes in the program of all-inclusive care for the elderly (PACE). Gerontologist. 2006; 46(2): 227-237. [PubMed: 16581887]

65. Wieland D, Boland R, Baskins J, Kinosian B. Five-year survival in a program of all-inclusive care for elderly compared with alternative institutional and home- and community-based care. $\mathrm{J}$ Geronotology A Biol Sci Medical Sci. 2010; 65(7):721-726.

66. Sullivan-Marx EM, Bradway C, Barnsteiner J. Innovative collaborations: A case study for academic owned nursing practice. J Nurs Scholarsh. 2010; 42(1):50-57. [PubMed: 20487186]

67. Li GK, Phillips C, Weber K. On lok: A successful approach to aging at home. Healthc Pap. 2009; 10(1):44-49. discussion 79-83. [PubMed: 20057216]

68. Mason DJ, Jones DA, Roy C, Sullivan CG, Wood LJ. Commonalities of nurse-designed models of health care. Nurs Outlook. 2015; 63(5):540-553. [PubMed: 26211847]

69. Fraher, E.; Spetz, J.; Naylor, M. Nursing in a transformed health care system: New roles, new rules. Philadelphia, PA: Leonard Davis Institute of Health Economics. Interdisciplinary Nursing Quality Research Initiative; 2015.

70. Patient Protection and Affordable Care Act (ACA). [Accessed January 6, 2016] 42 U.S.C. § 18001 et seq. 2010. www.hhs.gov/healthcare/rights/law/index.html

71. Porter ME. What is value in health care? N Engl J Med. 2010; 363:2477-2481. [PubMed: 21142528]

72. [Accessed January 4, 2016] HHS.gov. Better, smarter, healthier: In historic announcement, HHS sets clear goals and timeline for shifting medicare reimbursements from volume to value. 2015 . http://www.hhs.gov/about/news/2015/01/26/better-smarter-healthier-in-historic-announcementhhs-sets-clear-goals-and-timeline-for-shifting-medicare-reimbursements-from-volume-tovalue.html. Updated 2015

73. Naylor, MD. Building the health workforce as we transform the delivery system; Proceedings: The Commonwealth Fund-Neffield Trust 15th International Meeting on the Quality and Efficiency of Health Care; 2015.

74. Interprofessional Education Collaborative Expert Panel. Core competencies for interprofessional collaborative practice: Report of an expert panel. Washington, D. C.: Interprofessional Education Collaborative; 2011.

75. Institute of Medicine. The future of nursing: Leading change, advancing health. Washington, D.C.: The National Academies Press; 2011.

76. American Association of Colleges of Nursing. Employment of new nurse graduates and employer preferences for baccalaureate-prepared nurses. research brief. http://www.aacn.nche.edu/leadinginitiatives/research-data/Research-Brief-2014.pdf.

77. Cox, M.; Naylor, M. Proceedings of a Conference sponsored by the Josiah Macy Jr. Foundation in January 2013. New York: Josiah Macy Jr. Foundation; 2013. Transforming Patient Care: Aligning Interprofessional Education with Clinical Practice Redesign. Accessible at: http:// macyfoundation.org/docs/macy_pubs/TransformingPatientCare_ConferenceRec.pdf 
78. Institute of Medicine. National Cancer Policy Forum. https://iom.nationalacademies.org/Activities/ Disease/NCPF.aspx. Updated 2015.

79. Nevidjon B. A seat at the table: Redesigning cancer care. Clin J of Oncol Nurs. 2014; 18(1):13-14. [PubMed: 24476719]

80. Kroenke K, Spitzer RL, Williams JB. The PHQ-9: Validity of a brief depression severity measure. J Gen Intern Med. 2001; 16(9):606-613. [PubMed: 11556941]

81. Heidrich SM, Egan JJ, Hengudomsub P, Randolph SM. Symptoms, symptom beliefs, and quality of life of older breast cancer survivors: A comparative study. Oncol Nurs Forum. 2006; 33(2):315322. [PubMed: 16518447]

82. Zarit SH, Reever KE, Bach-Peterson J. Relatives of the impaired elderly: Correlates of feelings of burden. Gerontologist. 1980; 20(6):649-655. [PubMed: 7203086]

83. Aging With Dignity. Five wishes. https://agingwithdignity.org/five-wishes/about-five-wishes. 


\section{Table 1}

Defining Function, Activities of Daily Living, and Instrumental Activities of Daily Living In the Context of Oncology and Geriatric Principles

- Function refers to the physical and mental function needed to meet daily needs, interact with friends and family, and perform work.

- Self-reported measures of function include activities of daily living (ADLs) and instrumental activities of daily living (IADLs).

- Activities of daily living are the basic self-care skills required to maintain independence at home. Instrumental activities of daily living are more complex skills that are necessary to maintain independence in the community. ${ }^{16}$ 